\title{
Kinerja Metode Perhitungan Premi Program Asuransi Usaha Tani Padi di Indonesia
}

\author{
ACENG KOMARUdIN MUTAQIN \\ Program Studi Statistika, Universitas Islam Bandung \\ Jl. Ranggamalela No. 1 Bandung \\ Email: aceng.k.mutaqin@gmail.com
}

\begin{abstract}
ABSTRAK
Metode yang sifatnya parametrik untuk menghitung premi pada program asuransi usaha tani padi di Indonesia telah dibahas oleh Mutaqin dkk. (2015) dengan mengasumsikan bahwa data hasil panen padinya berasal dari suatu populasi yang berdistribusi normal. Metode tersebut juga telah diaplikasikan terhadap data produktivitas padi di beberapa kabupaten di provinsi Jawa Barat. Dalam makalah ini metode tersebut akan dievaluasi kinerjanya dengan menggunakan simulasi Monte Carlo berdasarkan nilai rata-rata kesalahan mutlak dari taksiran besarnya premi untuk melihat keakuratan dari hasil taksirannya. Hasil simulasi Monte Carlo menunjukkan bahwa metode yang diusulkan memiliki keakurasian yang semakin tinggi ketika membesarnya nilai rata-rata hasil panen padi per satuan luas, menurunnya simpangan baku hasil panen padi per satuan luas, atau meningkatnya ukuran sampel.
\end{abstract}

Kata Kunci: premi, distribusi normal, simulasi Monte Carlo, rata-rata kesalahan mutlak.

\section{PENDAHULUAN}

Pada musim tanam Oktober 2012 sampai Maret 2013, pemerintah Indonesia, dalam hal ini Kementerian Pertanian melakukan uji coba program Asuransi Usaha Tani Padi (AUTP) yang dialokasikan di provinsi Jawa Barat, Jawa Timur dan Sumatera Selatan. Pemerintah memberikan subsidi untuk pembayaran premi asuransi sebesar 80\% (Rp. 144.000,-/hektar), sedangkan sisanya sebesar 20\% (Rp. 36.000,-/hektar) menjadi tanggungan petani (Supartoyo, dan Kasmiati, 2013).

Salah satu tahapan penting dalam proses industri bisnis asuransi adalah penetapan besarnya premi yang harus dibayarkan oleh pemegang polis (Grize, 2014). Beberapa metode untuk menghitung besarnya premi asuransi pertanian telah dibahas oleh banyak peneliti. Metode yang sifatnya parametrik dibahas oleh Botts dan Bales (1958) dalam Bharamappanavara dkk. (2010) dan Goodwin (1994), Babcock dkk. (2004) dan Ozaki dkk. (2008). Metode yang sifatnya nonparametrik dibahas oleh Goodwin (1994), Hatt dkk. (2012), dan Ozaki dkk. (2008). Metode yang sifatnya Bayes dibahas oleh Ozaki (2009), Ozaki dan Silva (2009), dan Ramadan (2011). Sementara itu, Wang dkk. (2010) menerapkan model analisis survival untuk merancang premi asuransi pertanian.

Besarnya premi yang ditetapkan oleh pemerintah Indonesia untuk uji coba program asuransi AUTP tahun 2012-2013 didasarkan pada persentase nilai pertanggungan per hektar, yaitu sebesar 3\% per hektar dari nilai pertanggungan Rp. 6.000.000,- atau sebesar Rp. 180.000,pada pelaksanaan uji cobanya, cakupan lahan padi yang dapat dilaksanakan oleh PT. Jasindo seluas 623,12 hektar dengan total premi yang terkumpul sebesar Rp. 112.100.000,- Luas lahan padi petani yang terkena gagal panen seluruhnya mencapai 87,28 hektar dengan klaim yang diajukan sebesar Rp. 523.700.000,- atau 467\% dari nilai premi yang diterima PT. Jasindo (Supartoyo, dan Kasmiati, 2013). Oleh karena itu PT. Jasindo mengalami kerugian. Berdasarkan kejadian tersebut dibutuhkan metode yang tepat untuk menghitung besarnya premi program asuransi AUTP berdasarkan data hasil panen padi di Indonesia, sehingga pada pelaksanannya nanti di tahun 2015, pihak perusahaan asuransi tidak mengalami kerugian.

Mutaqin dkk. (2015) telah membahas metode yang sifatnya parametrik untuk menghitung premi pada program AUTP di Indonesia dengan mengasumsikan bahwa data hasil panen padinya berasal dari suatu populasi yang berdistribusi normal. Tujuan dari penulisan makalah 


\section{Aceng Komarudin Mutaqin}

ini adalah untuk mengevaluasi kinerja dari metode perhitungan premi yang dibahas oleh Mutaqin dkk. (2015) dengan menggunakan simulasi Monte Carlo.

\section{PROGRAM ASURANSI AUTP DI INDONESIA}

Berikut ini adalah beberapa hal penting yang terkait dengan skema asuransi AUTP di Indonesia:

1. Peserta asuransi dalam hal ini petani maksimal lahanya seluas 2 hektar.

2. Nilai pertanggungan adalah Rp. 6.000.000,- per hektar.

3. Premi asuransi AUTP adalah sebesar 3\% dari nilai pertanggungan atau sebesar Rp. 180.000,- per hektar. Pemerintah memberikan subsidi sebesar 80\% atau Rp. 144.000,per hektar, sedangkan petani membayar sebesar 20\% atau Rp. 36.000,- per hektar.

4. Jenis risiko yang dapat diasuransikan adalah kekeringan, banjir dan serangan Organisme Pengganggu Tumbuhan (OPT).

5. Jangka waktu pertanggungan asuransi berlaku untuk satu musim tanam.

6. Petani yang hanya panen maksimal sebesar $25 \%$ dari area yang ditanam akan memperoleh ganti rugi penuh sebesar Rp. 6.000.000,- Untuk kasus lainnya tergantung pada tingkat kerusakan dan usia tanam (Pasaribu, 2010).

\section{DISTRIBUSI NORMAL SEBAGAI SALAH SATU DISTRIBUSI HASIL PANEN}

Untuk pendekatan yang sifatnya parametrik, penentuan besarnya premi asuransi pertanian didasarkan pada distribusi dari hasil panen. Salah satu distribusi tersebut adalah distribusi normal. Misalkan peubah acak $Y$ berdistribusi normal, dengan parameter lokasi $-\infty<\mu<\infty$ dan parameter skala $\sigma^{2}>0$. Fungsi densitas dari peubah acak tersebut adalah:

$$
g(y)=\frac{1}{\sigma \sqrt{2 \pi}} \exp \left[-\frac{1}{2}\left(\frac{y-\mu}{\sigma}\right)^{2}\right] ;-\infty<y<\infty .
$$

Rata-rata dan varians dari peubah acak $Y$ masing-masing adalah $E(Y)=\mu$ dan $\operatorname{Var}(Y)=\sigma^{2}$.

Misalkan $Y_{1}, Y_{2}, \cdots, Y_{n}$ merupakan sampel acak berukuran $n$ dari distribusi normal di atas, maka taksiran parameter $\mu$ dan $\sigma^{2}$ dengan menggunakan metode kemungkinan maksimum (maximum likelihood estimation) masing-masing adalah $\hat{\mu}=\bar{Y}=\frac{1}{n} \sum_{i=1}^{n} Y_{i}$, dan $\hat{\sigma}^{2}=\frac{1}{n} \sum_{i=1}^{n}\left(Y_{i}-\bar{Y}\right)^{2}$. Taksiran $\hat{\sigma}^{2}$ bersifat bias. Taksiran tak-biasnya adalah $S^{2}=\frac{1}{n-1} \sum_{i=1}^{n}\left(Y_{i}-\bar{Y}\right)^{2}$.

\section{METODE PARAMETRIK UNTUK MENGHITUNG PREMI PROGRAM AUTP}

Misalkan $Y$ adalah peubah acak rata-rata hasil panen padi per hektar dari seorang petani, dengan fungsi densitas $g(y)$ dan ekspektasi $E(Y)$. Dalam program asuransi AUTP disebutkan bahwa petani yang hanya panen maksimal sebesar 25\% dari area yang ditanam akan memperoleh ganti rugi penuh sebesar Rp. 6.000.000,- Sedangkan untuk kasus lainnya tergantung pada tingkat kerusakan dan usia tanam (Pasaribu, 2010). Dengan mengacu pada pernyataan di atas, maka Mutaqin dkk. (2015) merumuskan besarnya ganti rugi untuk program asuransi AUTP. Misalkan I menyatakan peubah acak besarnya ganti rugi (dalam juta rupiah), maka

$$
I= \begin{cases}6 & ; \text { untuk } Y \leq 0,25 E(Y), \\ \frac{8}{E(Y)}(E(Y)-Y) & ; \text { untuk } 0,25 E(Y)<Y<E(Y), \\ 0 & ; \text { untuk } Y \geq E(Y) .\end{cases}
$$


Ekspektasi dari peubah acak besarnya ganti rugi, yaitu

$$
\begin{gathered}
E(I)=6 P(Y \leq 0,25 E(Y)) \\
+E\left[\frac{8}{E(Y)}(E(Y)-Y) \mid 0,25 E(Y)<Y<E(Y)\right] \times \\
P(0,25 E(Y)<Y<E(Y)) .
\end{gathered}
$$

Jika $Y$ diasumsikan berdistribusi normal dengan fungsi densitas sebagaimana dalam Persamaan (1), maka dapat ditunjukkan bahwa besarnya premi program asuransi AUTP yang adil secara aktuaria untuk kasus ini adalah

$$
E(I)=6 \Phi\left(\frac{-0,75 \mu}{\sigma}\right)-8 \frac{\sigma}{\mu}\left[\phi\left(\frac{-0,75 \mu}{\sigma}\right)-\frac{1}{\sqrt{2 \pi}}\right]
$$

dimana $\phi(\cdot)$ dan $\Phi(\cdot)$ masing-masing menyatakan nilai fungsi densitas peluang dan nilai fungsi distribusi kumulatif dari distribusi normal baku.

Dengan menggunakan prinsip plug-in, maka taksiran besarnya premi program asuransi AUTP untuk kasus distribusi normal adalah sama sebagaimana di atas, namun parameter $\mu$ dan $\sigma$ diganti oleh taksirannya yang tak bias, yaitu

$$
E(I)=6 \Phi\left(\frac{-0,75 \bar{Y}}{S}\right)-8 \frac{S}{\bar{Y}}\left[\phi\left(\frac{-0,75 \bar{Y}}{S}\right)-\frac{1}{\sqrt{2 \pi}}\right]
$$

\section{STUDI SIMULASI}

Dalam bagian ini akan dilakukan simulasi Monte Carlo untuk mengevaluasi kinerja metode perhitungan besarnya premi program asuransi AUTP di Indonesia menggunakan ukuran ratarata kesalahan mutlak (RKM). Simulasi Monte Carlo dilakukan 10.000 kali menggunakan perangkat lunak Matlab R2015a dengan mengasumsikan nilai parameter $\mu$ (rata-rata hasil panen padi per hektar) dan parameter $\sigma$ (simpangan baku hasil panen padi per hektar) dibuat hampir sama rata-rata dan simpangan baku produktivitas padi di kabupaten-kabupaten di provinsi Jawa Barat (BPS Provinsi Jawa Barat, 2015). Nilai parameter yang akan dicobakan adalah $\mu=40,50,60,70$ dan $\sigma=3,4,5,6$. Tabel 1 menyajikan kasus-kasus untuk kombinasi parameter tersebut. Sementara itu, ukuran sampel yang akan dicobakan adalah $n=20,50$, 100, 1.000. Tabel 2 dan 3 menyajikan hasil simulasi untuk berbagai kasus data yang dicobakan.

Tabel 1. Berbagai Kasus Data yang akan Dibangkitkan

\begin{tabular}{ccc}
\hline Kasus & Nilai $\mu$ & Nilai $\sigma$ \\
\hline 1 & 40 & 3 \\
2 & 40 & 4 \\
3 & 40 & 5 \\
4 & 40 & 6 \\
5 & 50 & 3 \\
6 & 50 & 4 \\
7 & 50 & 5 \\
8 & 50 & 6 \\
9 & 60 & 3 \\
10 & 60 & 4 \\
11 & 60 & 5 \\
12 & 60 & 6 \\
13 & 70 & 3 \\
14 & 70 & 4 \\
15 & 70 & 5 \\
16 & 70 & 6 \\
\hline
\end{tabular}




\section{Aceng Komarudin Mutaqin}

Tabel 2. Hasil Simulasi Monte Carlo untuk $n=20$ dan $n=50$

\begin{tabular}{cccccc}
\hline & & \multicolumn{2}{c}{$n=20$} & \multicolumn{2}{c}{$n=50$} \\
\cline { 3 - 6 } Kasus & $\begin{array}{c}\text { Nilai Premi } \\
\text { Sebenarnya } \\
\text { (rupiah) }\end{array}$ & $\begin{array}{c}\text { Rata-rata } \\
\text { Taksiran Premi } \\
\text { (rupiah) }\end{array}$ & $\begin{array}{c}\text { Nilai RKM } \\
\text { (rupiah) }\end{array}$ & $\begin{array}{c}\text { Rata-rata } \\
\text { Taksiran Premi } \\
\text { (rupiah) }\end{array}$ & $\begin{array}{c}\text { Nilai RKM } \\
\text { (rupiah) }\end{array}$ \\
\hline 1 & 239.365 & 236.810 & 30.973 & 238.164 & 19,471 \\
2 & 319.154 & 314.308 & 42.133 & 317.695 & 25.649 \\
3 & 398.942 & 394.404 & 52.534 & 397.042 & 32.402 \\
4 & 478.731 & 472.709 & 62.945 & 476.395 & 39.402 \\
5 & 191.492 & 188.800 & 24.983 & 190.669 & 15.425 \\
6 & 255.323 & 252.042 & 33.587 & 253.740 & 20.848 \\
7 & 319.154 & 315.113 & 41.268 & 317.335 & 25.932 \\
8 & 382.985 & 377.772 & 50.195 & 381.326 & 31.271 \\
9 & 159.577 & 157.496 & 20.622 & 158.819 & 12.842 \\
10 & 212.769 & 210.586 & 27.741 & 210.951 & 17.336 \\
11 & 265.962 & 262.189 & 34.599 & 264.897 & 21.465 \\
12 & 319.154 & 315.114 & 41.981 & 317.766 & 26.022 \\
13 & 136.780 & 135.429 & 17.590 & 135.993 & 11.100 \\
14 & 182.374 & 180.229 & 23.794 & 181.430 & 14.927 \\
15 & 227.967 & 224.528 & 29.649 & 227.121 & 18.479 \\
16 & 273.560 & 269.663 & 35.715 & 271.977 & 22.224 \\
\hline
\end{tabular}

Berdasarkan nilai-nilai yang ada dalam Tabel 2 dan 3 terlihat bahwa untuk nilai $n$ dan $\sigma$ tertentu, dengan membesarnya nilai $\mu$, akan meningkatkan keakurasian nilai taksiran premi hasil dari metode yang diusulkan dalam penelitian ini. Hal ini terlihat dari nilai rata-rata RKM yang semakin mengecil. Keakurasian nilai taksiran premi hasil dari metode yang diusulkan dalam penelitian ini juga meningkat dengan menurunnya nilai $\sigma$ dan meningkatnya ukuran sampel.

Tabel 3. Hasil Simulasi Monte Carlo untuk $n=100$ dan $n=1.000$

\begin{tabular}{cccccc}
\hline & & \multicolumn{2}{c}{$n=100$} & \multicolumn{2}{c}{$n=1.000$} \\
\cline { 3 - 5 } Kasus & $\begin{array}{c}\text { Nilai Premi } \\
\text { Sebenarnya } \\
\text { (rupiah) }\end{array}$ & $\begin{array}{c}\text { Rata-rata } \\
\text { Taksiran Premi } \\
\text { (rupiah) }\end{array}$ & $\begin{array}{c}\text { Nilai RKM } \\
\text { (rupiah) }\end{array}$ & $\begin{array}{c}\text { Rata-rata } \\
\text { Taksiran Premi } \\
\text { (rupiah) }\end{array}$ & $\begin{array}{c}\text { Nilai RKM } \\
\text { (rupiah) }\end{array}$ \\
\hline 1 & 239.365 & 238.741 & 13.594 & 239.387 & 4.323 \\
2 & 319.154 & 318.404 & 18.109 & 319.047 & 5.765 \\
3 & 398.942 & 398.279 & 23.075 & 398.811 & 7.237 \\
4 & 478.731 & 477.500 & 28.038 & 478.589 & 8.731 \\
5 & 191.492 & 190.784 & 10.878 & 191.417 & 3.449 \\
6 & 255.323 & 254.500 & 14.719 & 255.256 & 4.617 \\
7 & 319.154 & 318.333 & 18.370 & 319.107 & 5.737 \\
8 & 382.985 & 381.961 & 22.078 & 382.826 & 6.967 \\
9 & 159.577 & 159.127 & 9.078 & 159.514 & 2.866 \\
10 & 212.769 & 212.308 & 12.216 & 212.724 & 3.816 \\
11 & 265.962 & 265.370 & 15.189 & 265.870 & 4.752 \\
12 & 319.154 & 318.504 & 18.128 & 319.009 & 5.758 \\
13 & 136.780 & 136.468 & 7.807 & 136.724 & 2.429 \\
14 & 182.374 & 181.990 & 10.264 & 182.284 & 3.280 \\
15 & 227.967 & 227.132 & 13.061 & 227.851 & 4.140 \\
16 & 273.560 & 273.193 & 15.599 & 273.550 & 4.965 \\
\hline
\end{tabular}




\section{KESIMPULAN}

Dalam makalah ini telah dilakukan evaluasi kinerja metode perhitungan premi program asuransi AUTP di Indonesia yang rencananya akan digulirkan di tahun 2015 yang mengasumsikan data hasil panen padi per hektar mengikuti distribusi normal. Hasil simulasi Monte Carlo menunjukkan bahwa metode yang diusulkan oleh Mutaqin dkk. (2015) memiliki keakurasian yang semakin tinggi ketika membesarnya nilai rata-rata hasil panen padi per satuan luas, menurunnya simpangan baku hasil panen padi per satuan luas, atau meningkatnya ukuran sampel.

\section{DAFTAR PUSTAKA}

Babcock, B. A., Hart, C. E., Hayes, D. J. 2004. Actuarial Fairness of Crop Insurance Rates with Constant Rate Relativities. American Journal of Agricultural Economics: Vol. 86, No. 3, 563-575.

Bharamappanavara, S. C., Hasanabadi, M. S., Handigol, J. A., Yeledalli, R. A. 2010. Alternative Model for Crop Insurance - A Case of Onion Crop (Allium Cepa). Proceedings of The International Conference On Applied Economics - ICOAE 2010, 85-90.

BPS Provinsi Jawa Barat. 2015. Produksi Padi, Jagung, dan Kedelai (Angka Sementara Tahun 2014). Berita Resmi Statistik: No. 19/03/32/Th. XVII, 2 Maret 2015.

Goodwin, B. K. 1994. Premium Rate Determination in the Federal Crop Insurance Program: What Do Averages Have to Say About Risk? Journal of Agricultural and Resource Economics: Vol. 19, No. 2, 382-395.

Grize, Y.-L. 2014. Applications of Statistics in the Field of General Insurance: An Overview. International Statistical Review, 1-25, doi:10.1111/insr.12066.

Hatt, M., Heyhoe, E., Whittle, L. 2012. Options for Insuring Australian Agricultural. Department of Agricultural, Fisheries and Forestry, Australian Bureau of Agricultural and Resource Economics and Sciences (ABARES). http://www.daff.gov.au/SiteCollectionDocuments/ag-food /drought/ec/nrac/work-prog/abares-report/abares-report-insurance-options.pdf. Diunduh pada tanggal 20 November 2014.

Mutaqin, A.K., Kudus, A., Karyana, Y. 2015. Metode Parametrik untuk Menghitung Premi Program Asuransi Usaha Tani Padi di Indonesia. Prosiding SNaPP 2015 Sains dan Teknologi, Universitas Islam Bandung, 15-23.

Ozaki, V. A. 2009. Pricing Farm-Level Agricultural Insurance: A Bayesian Approach. Empirical Economics: Vol. 36, 231-242.

Ozaki, V. A., Goodwin, B. K., Shirota, R. 2008. Parametric and Nonparametric Statistical Modelling of Crop Yield: Implications for Pricing Crop Insurance Contracts. Applied Economics: Vol. 48, 11511164.

Ozaki, V. A., Silva, R. S. 2009. Bayesian Ratemaking Procedure of Crop Insurance Contracts with Skewed Distribution. Journal of Applied Statistics: Vol. 36, No. 4, 443-452.

Pasaribu, S. M. 2010. Developing Rice Farm Insurance in Indonesia. Agriculture and Agricultural Science Procedia: Vol. 1, 33-41.

Ramadan, A. 2011. Empirical Bayes Nonparametric Density Estimation of Crop Yield Densities: Rating Crop Insurance Contracts. Thesis Program Master di The Faculty of Graduate Studies of The University of Guelph.

Supartoyo, Y. H., Kasmiati. 2013. Asuransi Pertanian sebagai Alternatif Mengatasi Risiko Usaha Tani Menuju Pertanian Berkelanjutan: Tinjauan https://www.academia.edu/4766244/ASURANSI _PERTANIAN_SEBAGAI_ALTERNATIF_MENGATASI_RISIKO_USAHA_TANI_MENUJU_PERTANIAN_ BERKELANJUTAN. diunduh pada tanggal 20 November 2014.

Wang, E., Yu, Y., Little, B. B., Li, Z. 2010. Crop Insurance Premium Design Based on Survival Analysis Model. Agriculture and Agricultural Science Prosedia: 1, 67-75. 